doses of the solid opium, either in pill or powder. Next to solid opium, Battley's sedative solution of opium is good; but morphia is much less useful in these hæcoorrhages, especially in the cataclysmic forms. Ice and brandy, champagne, or other suitable stimulants may be requisite; and, above all, Valentine's meat-juice is most valuable. Peptonised meats and other foods (Bonger's, Darby's, and others) may be useful adjuncts. In certain cases the hypodermic injection of ergotinine of $\mathrm{T}_{\mathrm{d}} \mathrm{n}$ et (Paris) may be helpful, and tincture of hamamelis may help in certain forms. The bladder should be relieved by catheterism with antiseptic precautions, as may be required. The use of astringents, such as gallic and other acids, is not great in these accidents, nor can $I$ recommend the use of heavy bags of ice to the abdomen. But besides medical treatment, certain grave surgical questions arise in some cases, and demand urgent solution : for example, in cases where there are reasonable grounds for suspecting the source of internal hæmorrhage to be a ruptured tubal or other pregaancy, and in similar accidents, such as bursting of a vein in the pampiniform plexus or else where, where the diagnosis is sufficiently clear; in short, in those cataclysmic intraperitoneal bleedings where rapid dissolution is threatened prompt operation may not only be justified, but b:come imperative to rescue the patient from impending death. It must not be forgotten, however, that even in ruptured ectopic gestations many patients recover without operation, as has happened several times within my own experience. The difficulty of accurate diagnosis is no doubt sometimes great, but not always; and when the well-bulanced judg. ment arrives at reasonable grounds for belief that hæmorrhage threatening to be rapidly fatal is going on unchecked from a controllable vascular lesion, then a bold, but not $r a s h$, interference is justifiable, and in these days of heroic abdominal surgery laparotomy should be done without delay. Daring the later stages of pelvic hrematoceles watchful supervision of the patient is necessary. The bladder should be carefully attended to with scrupulous cleanliness and great gentleness. B Bdsores should be prevented if possible. The bowels as a rule should be seldom opened. The mouth often becomes sore from the glazy and raw condition of the tongue and lips, therefore all food should be bland. Sedative mouth-washes give much relief (borax, myrrh, wine of opium, mucilages, and orange-flower or rose-water). The better patients are fed and cared for the sooner does the effusion disappear according to my experience. Care should be taken to guard against relapses or exacerbations, which are apt to occur about the time of the next catamenial period. I have been able occasionally to predist a fresh effusion at these epochs; and when such happens, it is followed by fresh manifestations of hæmatic jaundice. There is periodicity about these forms of hæmorrbage, and the ex planation of effusions occurring at the inter-menstrual or fortnightly periods is that it is part of a minor nisus that happens then. The condition of the vascular system will warn the physician, and the sphygmograph or finger may indicate in creased arterial tension, while the eye can see the venous turgescence. Undue vascular excitement may be reduced by aconite amyl-nitrite, nitro-glycerine, the bromides, \&c. The pelvic viscera may be quieted by actrea racemosa, monobromide of camphor, Indian hemp, conium, gelsemine, and so on, given internally, and by vaginal pessaries of iodoform, conia morphia, atropia, \&c., or by rectal suppositories. An atmospliere of turpentine ahout the sick chamber is good, both for styptic and purifying influences. With reference $t_{0}$ the puncture of hæmatoceles, I should, as a rule, depreeate opening, and would counsel caution in resorting to any operative measures. Should relief become necessary in the later stages from suspicion of suppuration or decomposition of blood, or from clear evidence of intolerable or dangerous tension, then aspirate by the vagina and not by the rectum ; but operation is generally undesirable, and should be carefully resorted to. During convalescence sea air and water will be found beneficial, and where absorption is tardy poultices of scalded seaweed and brine baths are essential The air of Harrogate is also good as promoting metabolism and occasionally iodine waters, notably those of Woodhall Spa, Horncastle, are good.

In conclusion, let me ask you to remember the two clinical points I would urge : the behaviour of effused blood according to its position, intra- or extra-peritoneally, and the symptom of hæmatic jaundice, slight or well-marked, from absorption of the colouring matter of the blood, and I believe you will find them helpful in your bedside practice.

\section{LONDON TEACHERS OF ANATOMY A RETROSPECT.}

BY CHARLES HAWKINS, F.R.C S.

In the obituary of Mr. Cesar Hawkins, pu'lished in THE LANCET of July $26 \mathrm{~h}$, it is statid that "he was the last member of the great Hunterian school founded by William Hunter in Great Windmill-street." Purhaps a few notes relative to those who taught in that school, as well as to some of the early days of anatomical teaching, will be interesting.

William Hunter may be said to have been the founder of anatomical schools in London. The first Act of Parliament respecting the practice of anatomy was passed in 1510 , in which it was recited " that the masters and governors of the Mystery and Commonality of Barbers and Surgeons' in London should take the bodies of four persons condemued and adjudged and put to death ; and make incision of the said dead bodies, or otherwise to order the same after their said discretion and pleasure for the further and better knowledge, instruction, insight, and learning in the said science or faculty of surgery." This Act was repealed by the Anatomy Act of 1832. The "Readers in Anatomy" at Barber-Surgeons' Hall were at first supplied by the College of Physicians. Caius, the pupil of Vesalius, is said to have been the first. In 1566 the United Company of Barbers and Surgeons passed a bye-law that no private anatomy be dissected out of the Hiall under a fine of $£ 10$. In $1596 \mathrm{Dr}$. (afterwards Sir William) Paddy was appointed Reader; in 1609 , Dr. Gwynne; in 1649 , Dr. (afterwards Sir Charles) Scarborough; in 1703, Dr. Mead. In 1629 the Company ordered "that the ancientest master should read the lectures, and so after every surgeon in his antiquity and degree in the Company." In 1645 Edward Arris paid $£ 300$ for the Company to establish an annual public anatomy ; in 1698 it was ordered "that there be an anatomy lecture called Gale's Anatomy."

In the beginning of 1700 private lecturing commenced. Cheselden, then twenty-two years old, lectured in 1711; Frank Nicholls in 1728; Nourse of St. Bartholomew's Hospital lectured at London House in Aldersgate-street in 1730 Bromfield of St. George's Hospital was elected anatomical demonstrator at Barber-Surgeons' Hall in 1744, Cheselden being one of the wardens. In 1746 William Hunter, a pupil of St. George's Hospital and a Member of the Corporation of Surgeons in 1747, succeeding Sharp, his teacher, commenced a course of lectures to a "Society of Navy Surgeons" in Covent-garden in the evening ; but Garrick, at that time appearing at another theatre, was a rival Hunter could not compete with, and finding his theatre deserted was com. pelled to lecture in the afternoon. At this period the courses of lectures were not extended over a length of time. Bromfield comprised anatomy and surgery in thirty-six lectures Nicholls professed to teach anatomy, physiology, and midwifery in thirty-nine; Nourse, the whole of anatomy in twenty-three. Hunter's first lecture produced about seventy guiveas, which he carried home in a bag, remarking that it was a larger sum than ever he had been master of; this was the nucleus of the fortune he subsequently acquired which enabled him to spend $£ 100,000$ on that magnificent collection now at Glasgow, although it is recorded that he was obliged to postpone the commencement of his third year's lectures on account of not having the wherewithal for necessary advertisements. He continued to teach in, I conclude, the house of his master, Douglas, where he lived until he removed, about 1750 , to Jermyn-street. In 1755 he admitted his brother as a partner in his lectures this arrangement ceased upon John Hunter going abroad in 1761 , and was never renewed, so that he was not a member of the Great Windmill-street School. At this time he was joined by Hewson; they parted company in 1770 upon a personal misunderstanding, he building a theatre in Cravenstreet, where he lectured, but died after a short illness in 1774.

In 1765 William Hunter applied to the Government to have granted him a piece of ground, part of that on which the National Gallery now stands, that he might erect a building fit for the purpose of a School of Anatomy, and supplied a plan "for a museum in London, for the improve. 
ment of anatomy, surgery, and physic." Upon this being declined, he commenced building the Hunterian School in Great Windmill-street, comprising a mansion, museum, theatre, and anatomical department. He removed into the house in 1768, resigning his house in Jermyn-street to John Hunter, where he lived until he removed to Leicester-square in 1783. Most accounts give the date as 1770 ; but the lists of the College of Physicians show that his address in 1767 was Jermyn-street, and Great Windmill-street in 1768. In 1771 he was joined by Cruickshank, who lectured until the day of his death in 1800. On March 15th, 1783, he commenced a course of lectures on Surgery, but was removed from the theatre in an insensible state, to die on the 30th of the same month. In 1784 his nephew, Mathew Baillie, joined Cruickshank in lecturing, and continued to do so until 1799. In 1785 James Wilson, a pupil of William and John Hunter, commenced as demonstrator to Baillie, and when he quitted the school he became joint lecturer with Cruickshank, and continued teaching until his death in 1821, which was as sudden as his predecessors', Hunter and Cruickshank. In 1807 Wilson purchased the freehold of the premises in Great Windmill-street, and inhabited the house, as Hunter and Baillie had previously done. $\mathrm{He}$ subsequently sold the property, reserving the school part of the premises on a lease. When Honoratus Leigh Thomas began to teach in Great Windmill-street I am not certain. Brodie found him there in 1802, and says in his Autobiography :- "He delivered only a few anatomical lectures. He was not fond of his vocation as a teacher, and was led to play truant a good deal." In 1805 he resigned, when Brodie commenced to teach in Great Windmill-street, which he continued to do until 1812, when Wilson proposed that he should take the school off his hands. This offer he declined, not possessing the funds required for the transfer. Thus ended his career as a teacher of anatomy. In 1808 he had commenced lecturing on surgery, and on parting from Wilson he took a house in Great Windmill-street, where he built a theatre and museum; these lectures he continued until 1830, when the school removed to St. George's Hospital. On Brodie's retirement from the school in 1812 Charles Bell joined Wilson. He had commenced lecturing in London in 1806. In one of those most interesting letters published in 1870which anybody wishing to have an insight of medical society at the commencement of the present century should read-he says : "I resolved to remain in London, and took a large ruinous house in Leicester-square, previously inhabited by Speaker Onslow. When I got into the house, the first night I slept in it, I had put ont the candle, and leaping into bed, the floor gave way under my foot, and I found that I had displaced the board. On examining this in the morning I discovered a tube under the loose board; it was the house where the 'invisible girl ' exhibited!" In a letter, October 7 th, 1812 , he says, "I gave my first lecture yesterday in Great Windmill-street. I gave an hour and a half to a full class; there were from eighty to a hundred, not gathered for the occasion, but pupils of the class." His brother-in-law, John Shaw, assisted him in his lectures and dissections until his death, which took place in 1827 . In one of his letters at this time he says: "I have lost my dear and best friend, Juhn Shaw. There is such a blank, I have not an idea left." In 1828 Bell opened the Medical School at University College, then called London University. On the institution of this school, Sir Benjamin Brodie was solicited by the Council to undertake the duties of either professor of anatomy or surgery, with any assistants he might wish to have. In 1826 Herbert Mayo and Casar Hawkins purchased Bell's interest in the school, he continuing to lecture in the session 1826-27, and they carried on the school until October, 1830, when Cæsar Hawkins left for the opening of St. George's Hospital School, and Mayo in 1831 for King's College. In the winter session of 1830.31 Mr. Thomas Tatum gave the anatomical demonstrations. Subsequently, Mr. Gregory Smith and Mr. Bushell delivered lectures. Mr. Smith afterwards removed to the school in Iittle Windmill-street, where Mr. Prescott Hewett joined him in October, 1836, as demonstrator previous to his being house-surgeon at St. George's Hospital in 1838.

I venture to add some criticisms on those I have mentioned as teachers. Baillie said of William Hunter: "He excelled very much any lecturer whom I have ever heard in the clearness of his arrangements, the aptness of his illustrations, and the elegance of his diction; he was perhaps the best teacher of anatomy that ever lived." Brodie, born the year William Hunter died, says in his Hunterian Oration, delivered in 1837 : "Hewson partook in no small degree of his master's zeal and industry, and his works show how much may be accomplished by means of these qualities when in. fused into a mind of moderate dimensions. Cruickshank, over-sensitive and hypochondriacal as he was from disease, was much superior to Hewson; his physiological papers in the Philosophical Transactions and his treatise on the absorbent vessels exhibit a combination of genius and learn. ing, and justify us in assigning him a very high place in the scale of men of genius." And in his Autobiography he says of Wilson: "He had a most profound knowledge of his subject, and his demonstrations were very far superior to those of any other anatomist of that day "-and I may, I believe, add to those of any one since.

In writing this sketch of a school I have been struck with an interesting intellectual lineage. A sister of William and John Hunter was the mother of Mathew Baillie and his gifted sister, the well-known authoress. Baillie married the daughter of the celebrated Dr. Denman, the father of the first Lord Denman, distinguished as a great lawyer. Dr. Denman married the aunt of Sir Benjamin Brodie. The second Sir B. Brodie, by his writings in science, gave evidence of his claim to be ranked as a distinguished professor of chemistry. Dr. Baillie's son, Mr. William Hunter Baillie, is one of the present trustees of the Hunterian Museum at the College of Surgeons.

Savile-row.

\section{OSTEOTOMY FOR GENU VALGUM.}

BY WILLIAM MACEWEN, M.D. GLASG., SURGEON AND LECTURER ON SURGERY, ROYAL INFIRMARY, AND SURGEON TO THE CHILDREN'S HOSPITAL, GLASGOW.

Osteotomy, as a means of cure of genu valgum, has been before the profession now for about seven years, and during the last three or four it has been very exten. sively adopted by surgeons over the civilised world. The present is therefore a fitting time for eliciting an ex. pression of opinion concerning it. From the manner in which the subject has been framed, I apprehend that we are not to discuss the various methods of treatment of genu valgum, but that we are to confine our attention to osteotomy for that disease. In the limited time at our disposal it is necessary that we confine our attention to a few points only I have considered that the two following could be discussed with advantage :-

1. The variou s methods of performing osteotomy for genu valgum and their comparative qualities.

2. The results of these operations.

As to the first point, we have to consider whether the intra- or the extra-articular method ought to be adopted, whether the femur or the tibia ought to be selected for the operation. It is presumed that all of the members are suff. ciently acquainted with the descriptions of Ogston's (and its various modifications), Billroth's, Schede's, Chiene's, and Macewen's operations to render it unnecessary to say any. thing on these points. It would be out of place in me to say anything as to the comparative qualities of these opera. tions, considering my close connexion with the last one mentioned. I have the more reason for doing this as I know that the gentlemen whose names are most closely identified with the various operations are present. Regarding the second question, I have gathered statistics which will belp the members in forming a conclusion on the subject.

A schedule was drawn out, asking for statistics concerning osteotomy for genu valgum, and a copy was addressed to every hospital surgeon in Britain. Replies have been received from about forty-five surgeons, but only thirty. seven of these have been able to answer the questions sufficiently fully to permit of them being of value. The statistics received have been formed into a table, which is here presented to the members of the International Medical Con. gress. The table must not be understood to be a complete one, inasmuch as many surgeons have not been able to reply, which it is hoped they will yet do. With regard to con. tinental and American surgeons, I trust to be able to arrange a similar scheme by which they may be inclined to favour

1 A paper read as introduction to a discussion on Osteotomy for Genu Valgum, International Medical Congress, Copenhagen, 1884. 